\title{
Design of Monitoring System for Linear Switched Reluctance Motor with Quadrature Encoder and Current Sensors
}

\author{
Mahir Dursun and Semih Ozden
}

\begin{abstract}
In this study, a monitoring system has been designed and implemented for Linear Switched Reluctance Motor (LSRM). Current wave, motor position and movement direction of LSRM was monitored on graphical LCD panel with a microcontroller. Linear incremental encoder was used to show position and movement direction of motor. Current of phases were sensed by sensors. Designed system was realized a LSRM with 6/4 poles, 3 phases, $250 \mathrm{~W}, 250 \mathrm{~N}$ pull forces which designed for driving an automatic door.
\end{abstract}

Index Terms-Linear switched reluctance motor, automatic door, monitoring, microcontroller.

\section{INTRODUCTION}

Opening and closing time of elevator doors significantly affects the elevator's service quality and waiting time of the passengers. Due to this reason, it is need to new design of sliding door drive systems which both quickly open and close and have low failure rate and at the same time high efficiency[1]. Especially, in the places where there has been a heavy traffic jam over elevators, subways, and trains, movement, velocity, efficiency and stability of door is important parameter for increasing comfort and quality [2].

Conventional elevator doors consist of an electromechanical lock and sliding door system connected to gear box, belt and pulley systems coupled with the shaft of a rotational motor. Cause of that equipment, there is mechanical loses and failure. Linear motors eliminate the need for rotary to linear mechanical interfaces resulting in simpler and robust conversion of electrical input into linear motion [3]. So, it is unavoidable to use linear motors in sliding door systems such as elevator doors. Linear Switched Reluctance Motor (LSRM) has simple construction, low cost, high pull forces, and accurate position. As an alternative to other AC and DC motors, they took place many practical fields in movement control systems. Higher efficiency in the LSRM which can be controlled with an appropriate converter circuit and driving system can be gained rather than the other electric motors [4]. Also LSRM doesn't need addition equipment such as wheel, belt and gear due to its linear motion naturally [2].

Manufacturing simplicity and high efficiency of rotational

Manuscript received September 14, 2012; revised November 29, 2012.

Mahir Dursun is with the Technology Faculty, Department of Electrical and Electronic Engineering, Gazi University, Turkey (e-mail: mdursun@gazi.edu.tr).

Semih Ozden is with the OSTIM Vocational School, Department of Electrical, Gazi University, Turkey (e-mail: semihozden@gmail.com). and linear SRM uses several industrial applications [5-10]. The present literature about LSRM is focused on application of transportation with accurate and rapid movement. In [11] and [12], the development of an LSRM is discussed mainly for transportation systems and the control output is velocity [13]. In [14] and [15], a detailed motor design procedure and the motor control algorithm are given and also its control output is again velocity. Fenercioglu and Dursun have published the design of a double-sided linear switched reluctance motor and its 3 dimensional magnetic analysis [16]. Similar studies are encountered in the literature [17]-[21].

In this study, a monitoring system designed for double-sided, 6/4 poled, 3 phased, $24 \mathrm{~V}, 250 \mathrm{~W}$ a LSRM having $250 \mathrm{~N}$ pull force used in locations such as elevators door. Current waves of phases were curved with current sensors. Analog output of sensors was sensed by a PIC18F452 microcontroller. Motor position was determined with a quadrature encoder pulses.

\section{LSRM AND SYSTEM DESIGN}

In conventional elevator doors, movement generally are achieved with a classical DC motors and sliding door system connected to gear box, belt and pulley systems coupled with the shaft of a rotational motor. This automatic door application type causes reduction of the velocity response of door and decrease of performance because of friction.

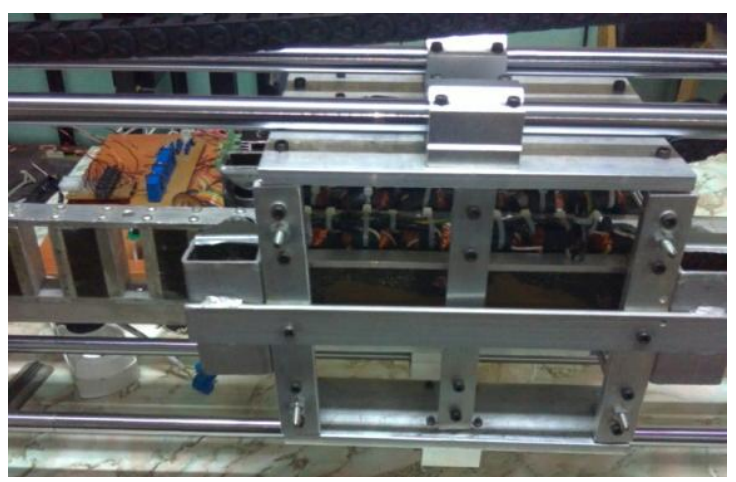

Fig. 1. Designed linear switched reluctance motor.

In this study monitoring system was designed for LSRM was used for driving automatic door. It may couple door directly. Furthermore, the power loss of electromechanical system was decreased and efficiency of system was decreased. Designed LSRM is shown Fig. 1. A monitoring system was aimed to guide studies on LSRM with quadrature 
encoder. Current waves of phases, position and direction of movement of motor were monitored on graphic LCD. Microchip brand PIC 18F452 was chosen as microcontroller.

\section{A. Current Monitoring}

Current waves of three phases were monitored independently. Thus, current shapes may observe. Current of phases was sensed by microcontroller analog-digital converter (ADC) feature. LEM brand LA 55-P model current sensor was used for sensing currents. Output of sensor analog value is input of ADC channel. Analog value was increased microcontroller level $(0-5 \mathrm{~V})$ by op-amps. Fig. 2 shows current measurement circuit of one phase.

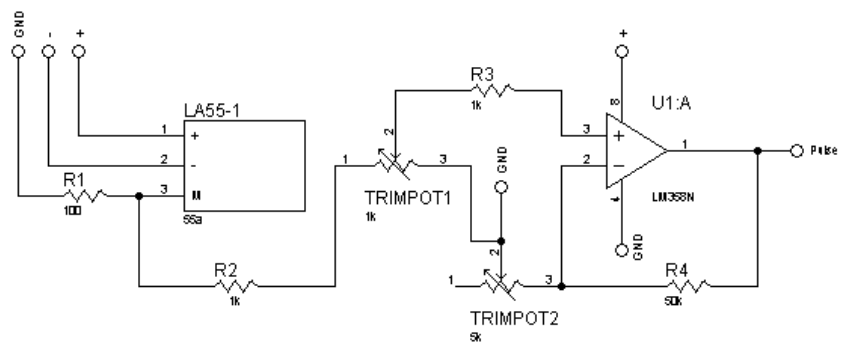

Fig. 2. Circuit of current sensor for one phase

Gain of LM358 opamp was adjusted with two potentiometers (trimpot 1 and 2). Offset value defined before measurement. Output of current sensor (LA55-1) was connected to gain step. In Fig. 3 shows views of current sensor circuit.

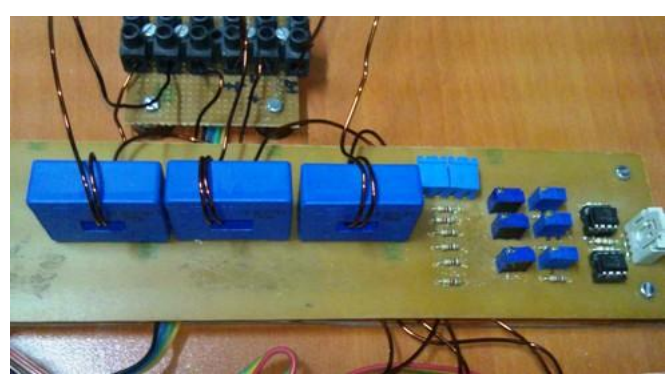

Fig. 3. View of current sensors circuit.

\section{B. Position Monitoring}

Position of motor was sensed by pulses of quadrature linear encoder. ATEK Sensor Technology brand MLS-1 encoder was chosen. It has $62.5 \mu \mathrm{m}$ pulse resolution and A, B and $\mathrm{Z}$ pulses. "A" and " $\mathrm{B}$ " are pulse signal, $\mathrm{Z}$ is index signal. There is a $90^{\circ}$ phase difference between $A$ and B. Output pulses and connection of linear encoder was shown in Fig. 4.
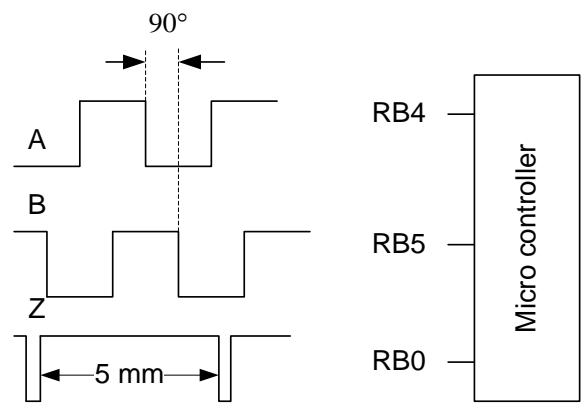

Fig. 4. Output pulses and connection of linear encoder.
Generally, capture feature of microcontroller uses for sensing pulses. But this option is only suitable for single pulse counting. A different alternative was used for quadrature counting. PIC has port changing interrupt (PORTB). If there is changing on "Port B", an interrupt occurs. So, output of encoder "A" signal connected RB4 pin and "B" signal RB5. Thus quadrature counting was achieved. "Z" index signal used for checking failure of counting. Encoder gives reset signal every $5 \mathrm{~mm}$. this signal was sensed by "RB0" interrupt. There are different interrupts. Index signal has high priority. Encoder signals and zones are given Fig. 5.

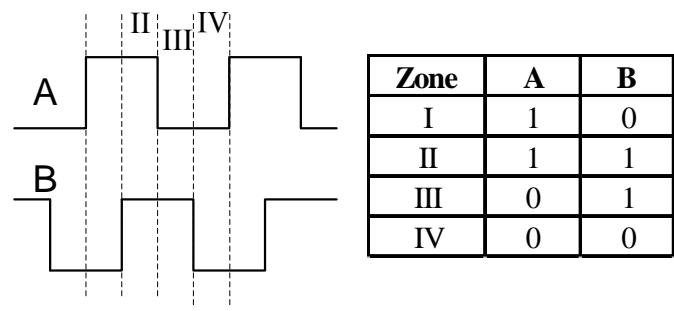

Fig. 5. Encoder signals and zones

Sequences of signals are gray code. Thus, only one bit changes. It gives very simplicity for sensing changing of movement direction. Flow chart of sensing direction is given in Fig. 5. When an interrupt occurred with sensing any chance on PortB4 to PortB7, firstly PORTB data saved as a new value. Direction of movement was achieved with XOR (exclusive OR) logic process "NewPortB.5" and "OldPortB.4". In this manner direction of motor was determine. On right side of Fig. 6, this determining system was shown. When direction was down, comparing bits are different every time and so result of XOR is "zero". When direction was up, comparing bits are same every time and so result of XOR is "one".

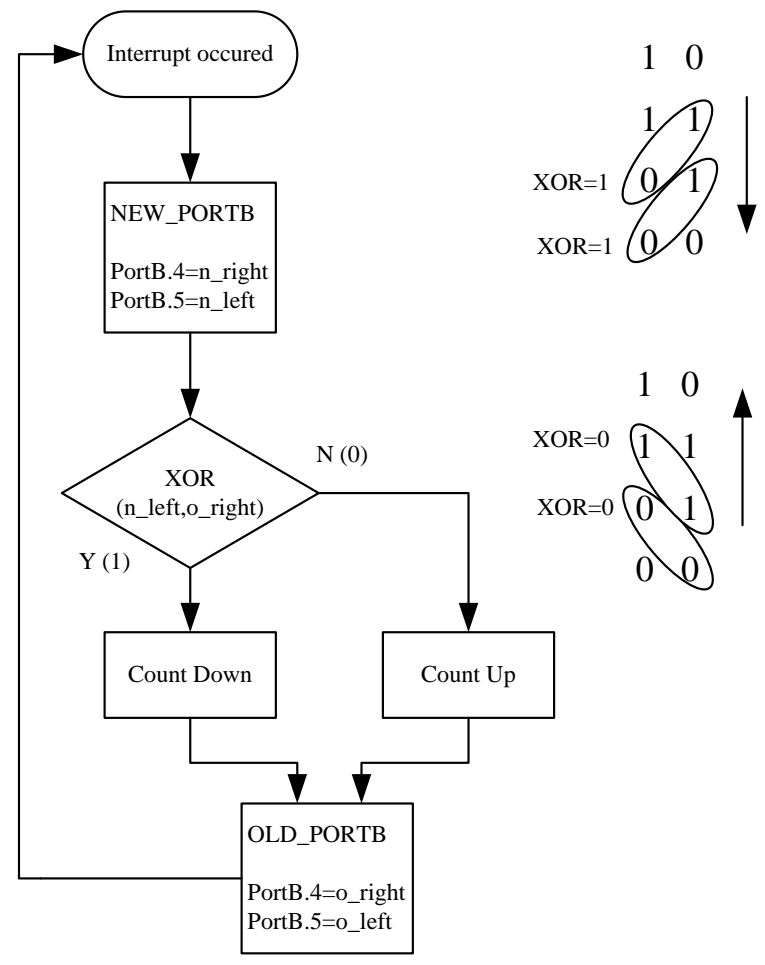

Fig. 6. Flow chart of sensing direction 


\section{HARDWARE OF SYSTEM}

Motor position must be known for operating LSRM. Encoder pulses must capture then motor phases can energize depending on motor position. Driving of graphic LCD (GLCD) cause delays so two different microcontroller was used. One of them controlled motor, another one drove GLCD. System's hardware of block diagram is shown Fig. 7 and view of it is shown Fig. 8. Circuit of LSRM's controller is given Fig. 9.

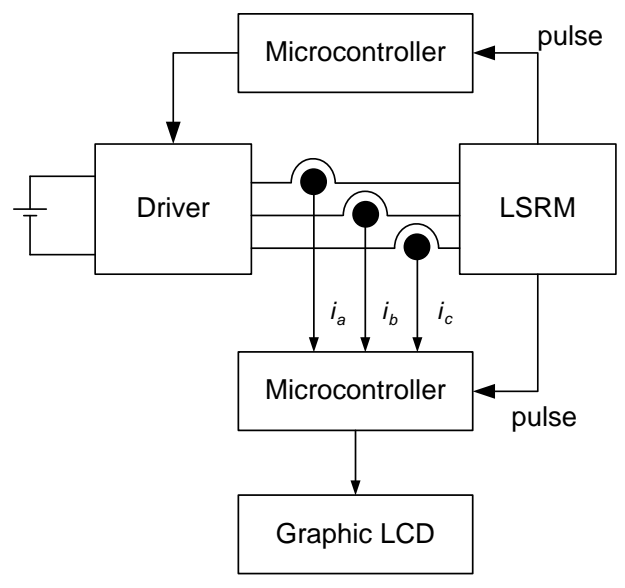

Fig. 7. Hardware of system

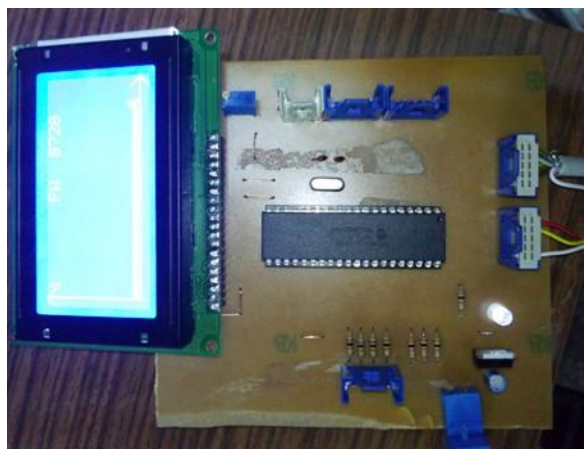

Fig. 8. View of system's hardware.

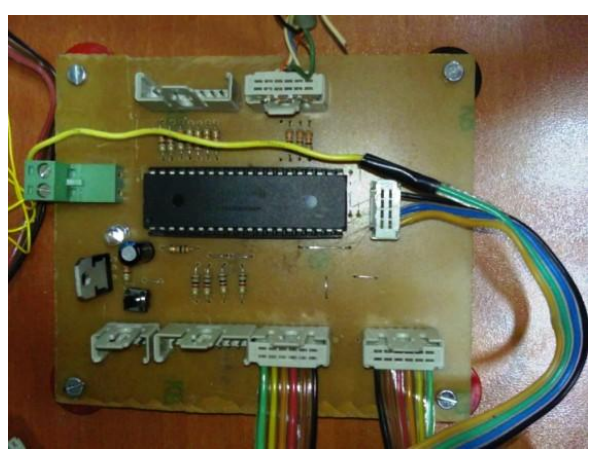

Fig. 9. Circuit of LSRM's controller.

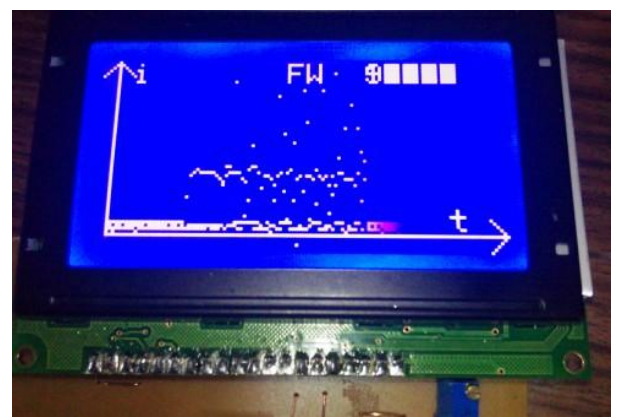

Fig. 10. View of GLCD panel (working).

\section{UNITS EXPERIMENTAL RESULTS}

Fig. 10 shows view of GLCD panel. Number of pulses and movement direction was shown on top of GLCD. It was not clear on screen cause of refreshing time of GLCD, but after stopping movement of motor it will be clear. "RW" and "FW" shows movement direction. Axis was created at initializing of system. Axis of $x$ is shown as time ( $t$ ). Axis of $y$ is shown as currents (i). Additionally some potentiometers and buttons can add system. Users may adjust input level of analog (currents) and time axis. Fig. 10 shows GLCD panel at acquiring data and curving. Fig. 11 shows at stand-by mode.

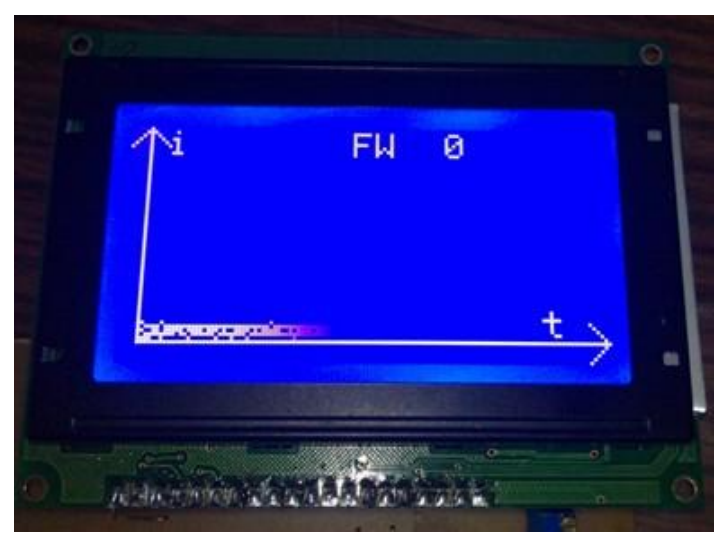

Fig. 11. View of GLCD panel (stand by).

\section{CONCLUSION}

In this study, a monitoring system has been designed and implemented for Linear Switched Reluctance Motor (LSRM) which used in locations such as elevators door. Current waves of phases, motor position and movement direction of LSRM were monitored on 128x64 pixels graphical LCD panel with a microcontroller. Another microcontroller was used for control of motor (energizing motor phases). Current waves of phases were curved with current sensors. Quadrature linear incremental encoder was used to show position and movement direction of motor. Current of phases were sensed by sensors. Designed system was tested on a LSRM with 6/4 poles, 3 phases, 250W, $250 \mathrm{~N}$ pull forces.

Motor position was sensed stability with $62.5 \mu \mathrm{m}$ sensitivity and also movement of direction was shown on GLCD panel. Current waves have been curved. This monitoring system leads studies on LSRM with low cost. Unbalanced currents may determine with using waves.

\section{REFERENCES}

[1] M. Dursun, F. Koc, and H. Ozbay, "Determination of geometric dimensions of a double sided linear switched reluctance motor," in Proc. International Conference on Electrical Machines and Power Electronics (ICEMPE 10), Paris, pp. 282-288, 2010.

[2] M. Dursun, F. Koc, H. Ozbay, and S. Ozden, "Design of linear switched reluctance motor driver for automatic door application," in Proc. International Conference on Information and Industrial Electronics (ICIIE), China, pp. 424-427, 2011.

[3] M. Dursun and F. Koc, "Simulation of fuzzy logic position and speed control of double sided linear switched reluctance motor," ICMSC in Proc. International Conference on Modeling, Simulation and Control, Egypt, pp. 517-521, 2010.

[4] J. L. Domingos, D. A. Andrade, M. A. A. Freitas, and H. D. Paula, "A new drive strategy for a linear switched reluctance motor," in Proc. 
IEEE International Electric Machines and Drives Conference (IEMDC'03), vol. 3, pp. 1714-1719, 2003.

[5] M. Dursun and S. Ozden, "Simulation and application of fuzzy logic controlled adjustable speed switched reluctance motor to elevator system," Journal of Polytechnic, vol. 11, no. 2, pp. 129-137, 2008.

[6] M. Dursun, "A wheelchair with fuzzy logic controlled switched reluctance motor supplied by PV arrays," Journal of Applied Sciences, vol. 8, no. 19, pp.3351-3360, 2008.

[7] T. J. E. Miller, Switched Reluctance Motor and Their Control, London, U.K.: Oxford Univ. Press, 1993.

[8] P. C. Kjaer, J. J. Gribble, and T. J. E. Miller, "High-grade control of switched reluctance machines," IEEE Trans. Ind. Electron., vol. 33, pp. 1585-1593, Dec. 1997.

[9] D. M. Dawson, J. Hu, and T. C. Burg, Nonlinear Control of Electric Machinery, New York: Marcel Dekker, 1998.

[10] I. Boldea and S. A. Nasar, Linear Electric Actuators and Generators, Cambridge, U.K.: Cambridge Univ. Press, 1997.

[11] C. T. Liu and J. L. Kuo, "Experimental investigation and 3-D modeling of linear variable-reluctance machine with magnetic-flux decoupled windings," IEEE Trans. Magn., vol. 30, pp. 4737-4739, Nov. 1994.

[12] C. T. Liu, L. F. Chen, J. L. Kuo, Y. N. Chen, Y. J. Lee, and C. T. Leu, "Microcomputer control implementation of transverse flux linear switched reluctance machine with rule-based compensator," IEEE Trans. Energy Conversion, vol. 11, pp. 70-75, Mar. 1996.

[13] H.S Lim and R. Krishnan, "Ropeless elevator with linear switched reluctance motor drive actuation systems," IEEE Transactions on Industrial Electronics, vol. 54, no. 4, pp. 2209-2218, August 2007.

[14] H. K. Bae, B. S. Lee, P. Vijayraghavan, and R. Krishnan, "A linear switched reluctance motor: converter and control," IEEE Trans. Ind. Applicat., vol. 36, pp. 1351-1359, Sept./Oct. 2000.

[15] B. S. Lee, H. K. Bae, P. Vijayraghavan, and R. Krishnan, "Design of a linear switched reluctance machine," IEEE Trans. Ind. Applicat. vol.36, pp. 1571-1580, Nov./Dec. 2000.

[16] A. Fenercioglu and M. Dursun, "Design and magnetic analysis of a double sided linear switched reluctance motor," Source: Przeglad Elektrotechniczny, vol. 86, no. 5, pp. 78-82, 2010.

[17] W. C. Gan and N. C. Cheung, "Design of a linear switched reluctance motor for high precision applications," IEEE International Electric Machines and Drives Conference (IEMDC), USA, pp.701-704, 2001.

[18] M. M. Thet, "Design and calculation of $75 \mathrm{~W}$ three-phase linear switch reluctance motor," Proceedings of World Academy of Science. Engineering and Technology, vol. 48, pp. 108-113, 2008.
[19] H. S. Lim, R. Krishnan, and N. S. Lobo, "Design and control of a linear propulsion system for an elevator using linear switched reluctance motor drives," IEEE Trans. On Ind. Elect, vol. 55, no. 2, pp. 534-542, 2008.

[20] X. Liu, Y. Y. Ye, and Z. Zheng, "A novel tubular permanent magnet linear synchronous motor used for elevator door," Electrical Machines and Systems Conference, Seoul, pp.801-804, 2007.

[21] L. Kolomeitsev, D. Kraynov, S. Pakhomin, F. Rednov, E. Kallenbach, V. Kireev, T. Schneider, and J. Böcker, "Linear switched reluctance motor as a high efficiency propulsion system for railway vehicles," International Symposium on Power Electronics, Electrical Drives, Automation and Motion (SPEEDAM 2008), Ischia, pp. 155-160, 2008

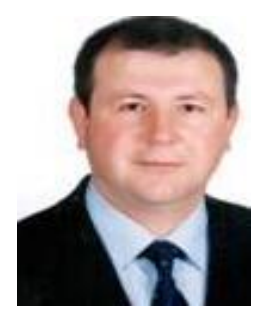

M. Dursun was born in 1970, Corum, Turkey. He received the BS degree in 1993, the MSc degree in 1996, and the PhD degree 2002 from Gazi University, Ankara, Turkey. He is currently study Assoc. Professor at the Technology Faculty, Department of Electrical and Electronic Engineering, Gazi University. His research interests include, Motor Design, Modeling, Motor Control, Switched Reluctance Motors, Linear Switched Reluctance Motors, Brushless DC motors, DC-DC converters, Matrix Converters, FLC, Artificial Neural Network, Elevator motors, Motor and Centrifugal Pump Drivers, DSP, PLC, microprocessors and microcontroller programming, serial and parallel active power filters, and photovoltaic systems, photovoltaic irrigating systems, RF control and communications, and distance education material design.

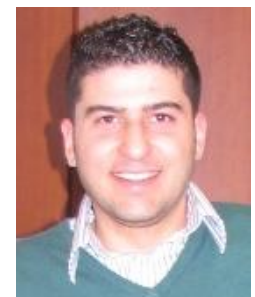

Semih Ozden was born in 1982, Aydın, Turkey. He received the BS degree in 2004, the MSc degree in 2007 from Gazi University, Ankara, Turkey and is now PhD student of Department of Electric Education, Gazi University. His research interests include photovoltaic systems, photovoltaic irrigating systems, switched reluctance motors, linear switched reluctance motors, motor control and controllers. His PhD's subject is "Design of PV powered smart drip irrigation system for dwarf cherry trees". 